\title{
Erratum to: Lamellar macular hole in high myopic eyes with posterior staphyloma: morphological and functional characteristics
}

\author{
Rino Frisina $^{1} \cdot$ Elena Zampedri $^{1}$ - Ivan Marchesoni ${ }^{1} \cdot$ Paolo Bosio $^{1} \cdot$ Barbara Parolini $^{2}$. \\ Federica Romanelli ${ }^{1}$
}

Published online: 12 May 2016

(C) Springer-Verlag Berlin Heidelberg 2016

Erratum to: Graefes Arch Clin Exp Ophthalmol

DOI 10.1007/s00417-016-3371-5

The errors are the following: authors and affiliations:

Rino $\mathrm{F}^{1}$, Elena $\mathrm{Z}^{2}$, Ivan $\mathrm{M}^{2}$, Paolo $\mathrm{B}^{2}$, Barbara $\mathrm{P}^{3}$, Federica $\mathrm{R}^{2}$. ${ }^{1}$ Multizonal Unit of Ophthalmology of Autonomous Province of Trento (TN), Square Santa Maria n. 6, 38068, Rovereto, Trento, Italy. frisinarino@gmail.com.

${ }^{2}$ Multizonal Unit of Ophthalmology of Autonomous Province of Trento (TN), Square Santa Maria n. 6, 38068, Rovereto, Trento, Italy.

${ }^{3}$ Department of Ophthalmology of Sant'Anna Institute, Brescia, BS, Italy.

Correct authors names and affiliations are the following: Frisina $\mathrm{R}^{1}$, Zampedri $\mathrm{E}^{1}$, Marchesoni $\mathrm{I}^{1}$, Bosio $\mathrm{P}^{1}$, Parolini $\mathrm{B}^{2}$, Romanelli $\mathrm{F}^{1}$.

${ }^{1}$ Multizonal Unit of Ophthalmology of Autonomous Province of Trento (TN), Square Santa Maria n. 6, 38068, Rovereto, Trento, Italy.

${ }^{2}$ Department of Ophthalmology of Sant'Anna Institute, Brescia, BS, Italy.

The online version of the original article can be found at http://dx.doi.org/ 10.1007/s00417-016-3371-5.

Rino Frisina

frisinarino@gmail.com

Multizonal Unit of Ophthalmology of Autonomous Province of Trento (TN), Square Santa Maria n. 6, 38068 Rovereto, Trento, Italy

2 Department of Ophthalmology of Sant'Anna Institute, Brescia, BS, Italy 